\title{
Animal data jeopardized by life behind bars
}

\section{Jonathan Knight, San Francisco}

Research animals raised in standard laboratory cages appear to develop a brain defect that could affect the outcome of experiments, according to behavioural scientists.

The findings, presented last week at the 35 th Congress of the International Society for Applied Ethology at the University of California, Davis, are likely to spark debate among neuroscientists about the wisdom of keeping laboratory mice in austere, standard cages.

Cages that provide more stimulating environments for animals could help solve the problem, researchers say. But space constraints and concerns about standardization of experiments have so far kept such innovations out of most animal research facilities.

Previous studies established that adding nesting material or littermates to cages increases the number and density of neurons in animals' brains. Rats and mice in enriched cages also perform better in memory tests (see Nature Rev. Neurosci. 1, 191-198; 2000).

Even so, their less astute cohorts reared alone in standard shoebox-sized cages have still been regarded by most researchers as normal. But the new evidence - presented by Joseph Garner, a behavioural scientist at the University of California, Davis - challenges that assumption. Garner's data suggest that the brains of animals housed in barren environments are severely abnormal.

Caged animals often develop repetitive behaviour patterns called stereotypies, Garner said. They pace, groom themselves incessantly, or gnaw the bars of the cage for hours.

In humans, stereotypies are thought to indicate brain damage in a region of the brain known as the basal ganglia, which regulates the initiation of movements. But cageinduced stereotypies have been regarded as merely excessive indulgence in normal behaviour, caused by an abnormal environment.

Garner and his colleagues said that they have now shown that the stereotypies reflect permanent brain dysfunction in parrots. Garner monitored parrot behaviour with a

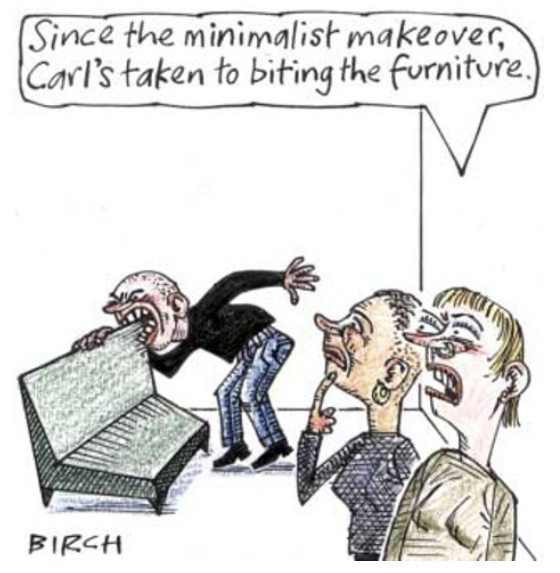

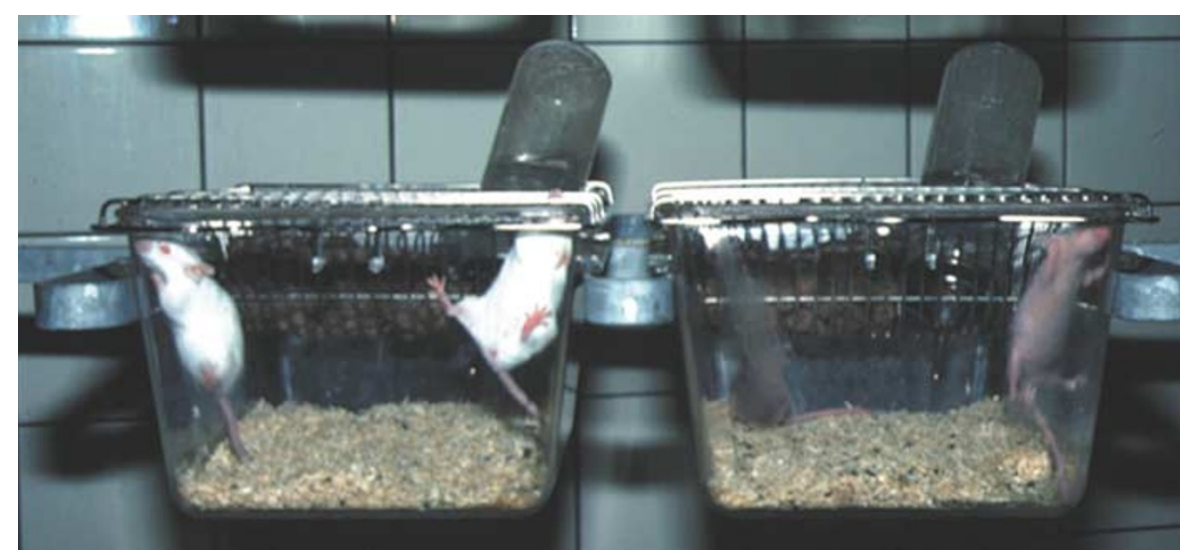

Stir crazy: mice housed in standard lab cages exhibit a range of abnormal repetitive behaviours.

psychological test normally used to diagnose damage to the basal ganglia in humans. The birds that showed little or no stereotypic behaviour did best on the test, whereas those that spent a lot of time in repeated featherplucking, for example, failed the test.

Garner believes that the result links the stereotypies to brain defects, and probably applies across species. He has already completed similar studies in voles and is now beginning to work with mice.

Cage-induced stereotypies were not known in rats and mice until 1996, when Hanno Würbel, an animal behaviourist at the Swiss Federal Institute of Technology in Zurich, used an infrared camera to record the behaviour of these nocturnal creatures at night. In the dark, the vast majority of mice engaged in behaviours such as repetitive bar biting and cage scratching. But most people who work with mice are unaware of the problem, because they only handle the animals in the light.

Even if brain defects turn out to be widespread in cage-reared animals, it is not clear how this will affect research. For many types of experiment, it may matter little. "If the process being studied is fundamental, it should reveal itself over and above these differences," says Fred Gage, a neurobiologist at the Salk Institute in La Jolla, California.

"The stereotypy effects might not matter if theywere the same across all labs," says Georgia Mason, a zoologist at the University of Oxford and Garner's graduate adviser. "But what we find is that stereotypy varies quite a bit."

"The irony is that all this barren environment that has been put upon animals for standardization may be the source of the variability," Garner says.

\section{Chemistry journal reacts to dispute}

\section{David Adam}

A chemistry journal plans to deal with an acrimonious dispute over a submitted paper by taking the unusual step of publishing it along with an addendum that disputes some of its conclusions.

Langmuir, which is published by the American Chemical Society, is planning to publish the nanotechnology paper on its website this week. An addendum states that the scientist who supervised the work takes issue with some of its content, its ownership and aspects of how the work was carried out.

The paper, written by Peter Schwartz, a physicist now at California Polytechnic State University, describes a way of patterning very thin lines of DNA onto a gold surface. Schwartz says he developed the technique while working in the laboratory of chemistry professor Chad Mirkin at Northwestern University, Illinois. Schwartz left Northwestern in August 2000 following several disagreements with Mirkin.

Langmuir accepted the peer-reviewed paper in March this year, but Mirkin effectively blocked its publication by writing to the society asserting that the data were incomplete and that Schwartz was trying to pass off collaborative research as his own. The journal agreed to publish the work only when Schwartz accepted the inclusion of the addendum. "The addendum solution is a compromise, but one that is not great for anyone involved," Mirkin says.

Schwartz - who believes that his results cast doubt on the performance of a different DNA micropatterning technique called 'dip pen lithography', developed by Mirkin's group - says he is "very relieved" that other researchers can now attempt to reproduce his work.

http://pubs.acs.org/journals/langd5/index.html 